\title{
Whole Genome Scan to Detect Chromosomal Regions Affecting Multiple Traits in Dairy Cattle
}

\author{
C. Schrooten, ${ }^{1,2}$ M. C. A. M. Bink, ${ }^{3}$ and H. Bovenhuis ${ }^{1}$ \\ ${ }^{1}$ Animal Breeding and Genetics Group, Wageningen Institute of Animal Sciences, \\ Wageningen University, The Netherlands \\ ${ }^{2}$ Holland Genetics, CR Delta, 6802 EB Arnhem, The Netherlands \\ ${ }^{3}$ Biometris, 6700 AC Wageningen, The Netherlands
}

\begin{abstract}
Chromosomal regions affecting multiple traits (multiple trait quantitative trait regions or MQR) in dairy cattle were detected using a method based on results from single trait analyses to detect quantitative trait loci (QTL). The covariance between contrasts for different traits in single trait regression analysis was computed. A chromosomal region was considered an $\mathrm{MQR}$ when the observed covariance between contrasts deviated from the expected covariance under the null hypothesis of no pleiotropy or close linkage. The expected covariance and the confidence interval for the expected covariance were determined by permutation of the data. Four categories of traits were analyzed: production (5 traits), udder conformation (6 traits), udder health (2 traits), and fertility (2 traits). The analysis of a granddaughter design involving 833 sons of 20 grandsires resulted in $59 \mathrm{MQR}(\alpha=0.01$, chromosomewise). Fifteen MQR were found on Bos taurus autosome (BTA) 14. Four or more MQR were found on BTA 6, 13, 19, 22, 23, and 25. Eight MQR involving udder conformation and udder health and $4 \mathrm{MQR}$ involving production traits and udder health were found. Five MQR were identified for combinations of fertility and udder conformation traits, and another $5 \mathrm{MQR}$ were identified for combinations of fertility and production traits. For 22 $\mathrm{MQR}$, the difference between the correlation attributable to the MQR and the overall genetic correlation was $>0.60$. Although the false discovery rate was relatively high (0.52), it was considered important to present these results to assess potential consequences of using these MQR for marker-assisted selection.
\end{abstract}

(Key words: genome scan, multiple trait, quantitative trait locus, dairy cattle)

Abbreviation key: BTA = Bos taurus autosome, MAS = marker-assisted selection, $\mathbf{M Q R}=$ multiple trait quantitative trait region.

Received June 3, 2003.

Accepted March 15, 2004.

Corresponding author: C. Schrooten; e-mail: chris.schrooten@ wur.nl.

\section{INTRODUCTION}

Breeding programs for livestock aim at improving the genetic level of several breeding goal traits by selection. These programs rely on phenotypic information on individuals and relationships between individuals. In the past decade, however, molecular techniques have become available that enable the genotypic analysis of animals. Analysis of phenotypic information on a trait and the genotype for genetic markers can lead to the identification of loci involved in the expression of the trait. In dairy cattle, many of these loci (QTL) have been reported for production traits (e.g., Georges et al., 1995; Spelman et al., 1996) as well as for conformation and functional traits (e.g., Ashwell et al., 1998; Schrooten et al., 2000). Efforts are now underway to identify the mutations responsible for the effects of QTL. Recently, a functional mutation in the DGAT1 gene on BTA (Bos taurus autosome) 14, responsible for large effects on production traits, has been identified (Grisart et al., 2002). A mutation in the growth hormone receptor gene on BTA 20 is associated with a strong effect on milk yield and composition (Blott et al., 2003). Genotypic information of the functional mutation or information on the genotype of closely linked markers can be incorporated in selection (marker-assisted selection; MAS), which is expected to increase genetic progress (e.g., Kashi et al., 1990; Meuwissen and van Arendonk, 1992).

Selection for a certain trait can lead to genetic changes in other traits because of the genetic correlations between the traits. One of the possible causes for genetic correlation is pleiotropy. Pleiotropic genes influence 2 or more traits. Closely linked QTL can also contribute to genetic correlation because of linkage disequilibrium. Pleiotropic effects of QTL, or closely linked QTL, each affecting a different trait, can affect the value of individual QTL for MAS.

The contribution of identified QTL to the overall genetic correlation can be determined by multiple trait QTL analysis. Multiple trait methods have been developed (e.g., Jiang and Zeng, 1995; Korol et al., 1995; Knott and Haley, 2000; Korol et al., 2001). Weller et 
al. (1996) developed a method to address the effect of QTL on multiple traits by canonical trait analysis. Schrooten and Bovenhuis (2002) showed that analysis of the covariance between contrasts from single trait analyses for different traits can reveal chromosomal regions affecting multiple traits (multiple trait quantitative trait regions; MQR). They developed a method that utilizes results from single trait QTL analyses to identify MQR in a granddaughter design. The method, however, cannot distinguish between pleiotropic QTL or closely linked QTL.

In this project, the method described by Schrooten and Bovenhuis (2002) is applied to data from a granddaughter design. The goal is to identify chromosomal regions affecting multiple traits $(\mathrm{MQR})$ in dairy cattle.

\section{MATERIALS AND METHODS}

Data from a granddaughter design (Weller et al., 1990), consisting of 20 Holstein-Friesian grandsires with 833 sons (Schrooten et al., 2000), were used in the analysis. The number of sons per grandsire ranged from 11 to 147 . For each animal, the genotype of 277 microsatellite markers on the 29 autosomes was determined. Per chromosome, the average interval between consecutive markers ranged from 4 to $29 \mathrm{cM}$ (Schrooten et al., 2000). Estimated breeding values based on progeny information were available for 37 routinely evaluated traits in The Netherlands and deregressed before analysis. A subset of 15 important breeding goal traits was chosen for the analysis, and they were divided into 4 categories: production ( $\mathrm{kg}$ milk, fat percentage, protein percentage, $\mathrm{kg}$ fat, and $\mathrm{kg}$ protein), udder conformation (fore udder attachment, front teat placement, teat length, udder depth, rear udder height, and central ligament), udder health (somatic cell score and milking speed), and fertility (interval calving - first insemination and nonreturn at $56 \mathrm{~d}$ after insemination). The number of sons with breeding values was 833 , except for milking speed $(\mathrm{n}=801)$, interval calving - first insemination $(\mathrm{n}=831)$, and nonreturn at $56 \mathrm{~d}$ after insemination $(\mathrm{n}=831)$. For each trait, contrasts between allelic effects were estimated by multi-marker regression (Knott et al., 1994) with the model

$$
\mathrm{y}_{\mathrm{ij}}=\mu+\mathrm{gs}_{\mathrm{i}}+\mathrm{b}_{\mathrm{ik}} \mathrm{X}_{\mathrm{ijk}}+\mathrm{e}_{\mathrm{ijk}}
$$

where $y_{i j}=$ deregressed breeding value of son $\mathrm{j}$ of grandsire $\mathrm{i}, \mu=$ overall mean, $\mathrm{gs}_{\mathrm{i}}=$ fixed effect of grandsire $\mathrm{i}, \mathrm{b}_{\mathrm{ik}}=$ regression coefficient for grandsire $\mathrm{i}$ at location $\mathrm{k}$ on the chromosome, $\mathrm{X}_{\mathrm{ijk}}=$ probability that son $\mathrm{j}$ receives a chromosomal segment from grandsire $i$ at position $\mathrm{k}$, and $\mathrm{e}_{\mathrm{ijk}}=$ random residual.
Significant QTL in the single trait analyses were determined by comparing the test statistic at each location with the $10 \%$ genomewise threshold, as described by Churchill and Doerge (1994). In this procedure, phenotypes were shuffled within families and reassigned to the sons, thus breaking the association between phenotypes and genotypes. Significance thresholds were obtained from analysis of 10,000 permuted data sets. A QTL was considered suggestive when the threshold would yield one false positive result in a genome scan (Churchill and Doerge, 1994). This threshold corresponds to a chromosomewise type I error $(\alpha)$ of 0.0345 .

To detect chromosomal regions affecting multiple traits, the covariance between estimated contrasts for pairs of traits, i.e., the regression coefficient in Equation (1), was determined at each location separately. As shown by Schrooten and Bovenhuis (2002), the expected covariance can be written as

$$
\begin{gathered}
\operatorname{cov}\left(\overline{\mathrm{v}_{\mathrm{i} 1 . .}}-\overline{\mathrm{v}_{\mathrm{i} 2 . .}}, \overline{\mathrm{w}_{\mathrm{i} 1 . .}}-\overline{\mathrm{w}_{\mathrm{i} 2 . .}}\right)= \\
\left\{\begin{array}{c}
\left.\frac{3 \mathrm{r}_{\mathrm{A}} \mathrm{h}_{\mathrm{v}} \mathrm{h}_{\mathrm{w}}+4 \mathrm{r}_{\mathrm{E}} \sqrt{1-\mathrm{h}_{\mathrm{v}}^{2}} \sqrt{1-\mathrm{h}_{\mathrm{w}}^{2}}}{\mathrm{n}_{\mathrm{s}} \mathrm{n}_{\mathrm{g}}}+\frac{3 / 4 \mathrm{r}_{\mathrm{A}} \mathrm{h}_{\mathrm{v}} \mathrm{h}_{\mathrm{w}}}{\mathrm{n}_{\mathrm{s}}}\right\} \sigma_{\mathrm{p}_{\mathrm{v}}} \sigma_{\mathrm{p}_{\mathrm{w}}}[2] \\
+1 / 4 \mathrm{p}_{\mathrm{het}} \mathrm{a}_{\mathrm{v}} \mathrm{a}_{\mathrm{w}}
\end{array}\right.
\end{gathered}
$$

where $\overline{v_{i 1} .}-\overline{v_{i 2} . .}$ and $\overline{\mathrm{w}_{11 . .}}-\overline{\mathrm{w}_{\mathrm{i} 2 . .}}=$ contrasts for trait $\mathrm{v}$ and $\mathrm{w}$ for grandsire $\mathrm{i} ; \mathrm{r}_{\mathrm{A}}=$ genetic correlation between trait $\mathrm{v}$ and trait $\mathrm{w} ; \mathrm{r}_{\mathrm{E}}=$ environmental correlation between trait $\mathrm{v}$ and trait $\mathrm{w} ; \mathrm{h}_{\mathrm{v}}^{2}$ and $\mathrm{h}_{\mathrm{w}}^{2}=$ heritabilities of trait $\mathrm{v}$ and trait $\mathrm{w}$, respectively; $\mathrm{n}_{\mathrm{s}}=$ number of sires per grandsire; $\mathrm{n}_{\mathrm{g}}=$ number of daughters per sire; $\sigma_{\mathrm{p}_{\mathrm{v}}}$ and $\sigma_{\mathrm{p}_{\mathrm{w}}}=$ phenotypic standard deviations of trait $\mathrm{v}$ and trait $\mathrm{w}$, respectively; $\mathrm{p}_{\text {het }}=$ fraction that is heterozygous for the QTL; and $a_{v}$ and $a_{w}=$ one-half the difference between the 2 homozygous genotypes (Falconer and Mackay, 1996), i.e., the allele substitution effect when there is no dominance. Note that parameter $b_{i k}$ in Equation (1) is an estimate of "a" in Equation (2). Standard deviations, heritabilities, and correlations do not include the effect of the QTL, i.e., these parameters are corrected for the effect of the QTL. A more detailed description of the method and discussion of its properties can be found in Schrooten and Bovenhuis (2002).

When there is no QTL, or the QTL affects only one trait, Equation (2) shows that the covariance does not depend on the values of $a_{v}$ and $a_{w}$, but solely on the polygenic and environmental parameters. Deviations from this expected covariance indicate the presence of an MQR, i.e., a pleiotropic QTL, or closely linked QTL, each affecting one of the traits. It is not possible to distinguish between QTL with a pleiotropic effect and closely linked QTL in a statistical analysis. In this pa- 


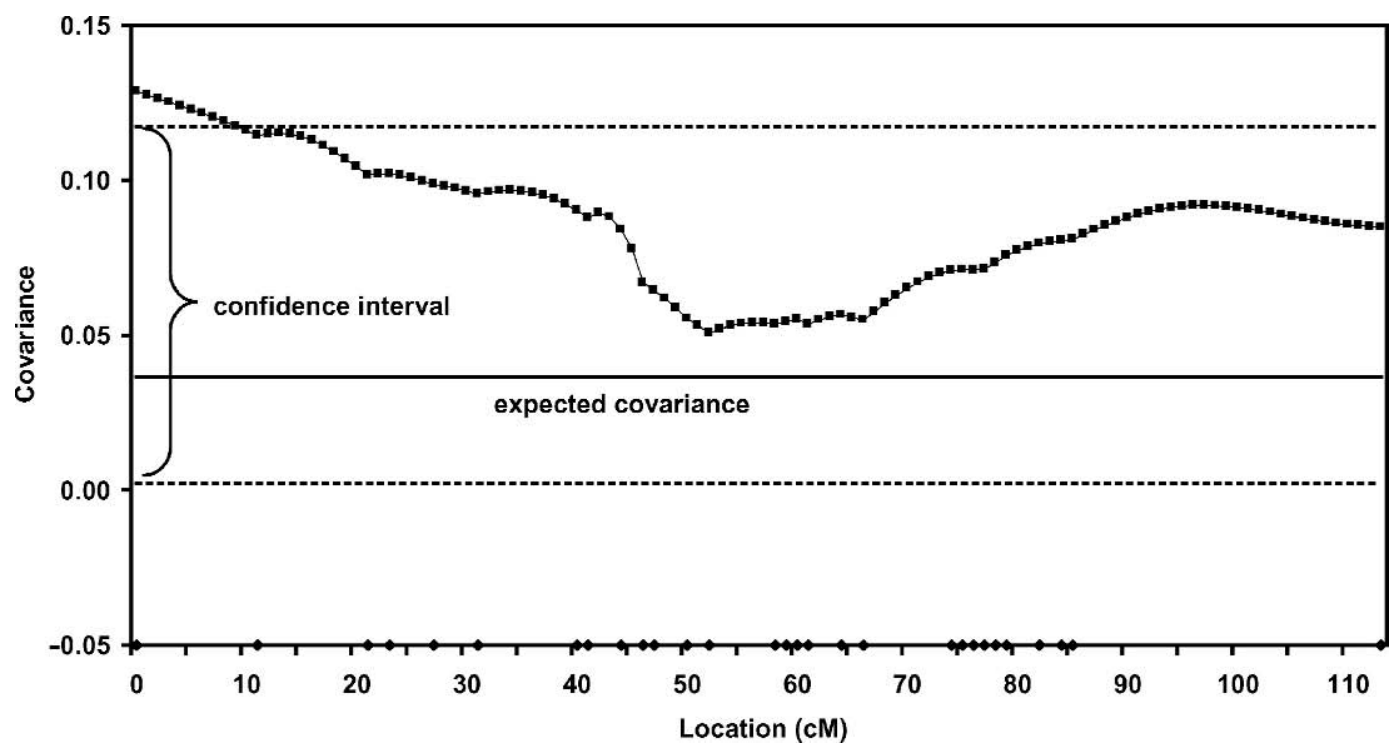

Figure 1. Covariance between contrasts for fat and protein percentages on Bos taurus autosome 6. Location of markers indicated by $(\diamond)$. Expected covariance (solid line) and 99\% confidence interval (broken lines) based on chromosomewise values.

per, we will therefore consider chromosomal regions affecting multiple traits (MQR), because pleiotropic QTL or closely linked QTL may be involved.

In the analysis, the expected covariance under the null hypothesis, i.e., a situation without a pleiotropic QTL or closely linked QTL, can be determined by calculating the average covariance in 10,000 permuted data sets. Permuted data sets were obtained as described for the single trait analysis. Here, permutation was also used to construct a 99\% confidence interval for the average or expected covariance. Covariances outside the confidence interval indicate that this chromosomal region is affecting both traits. Effects can have the same direction of change, i.e., the value of both traits is either increased or decreased, or have opposite direction of change. This can, in some cases, result in a large difference between the correlation because of the MQR and the overall genetic correlation. To detect chromosomal regions where this is the case, trait combinations with large differences between the $\mathrm{MQR}$ correlation and the overall genetic correlation were identified. Overall genetic correlations were not based on the data set used in the current project, but on data used for national evaluations (A. Harbers, 2003, personal communication).

\section{RESULTS}

\section{Example}

The method to detect $\mathrm{MQR}$ is based on the covariance between contrasts from single trait analyses. To illustrate the method, Figure 1 shows the results for fat percentage and protein percentage on BTA 6 . The covariance between contrasts is shown at 1-cM intervals. The expected covariance, determined from analyzing 10,000 permuted data sets, was 0.037 , with a $99 \%$ confidence interval ranging from 0.006 to 0.117 . The covariance in the region between 0 and $9 \mathrm{cM}$ exceeded the confidence interval. The largest deviation from the expected covariance was found at $0 \mathrm{cM}$. An increase in fat percentage caused by the QTL was accompanied by an increase in protein percentage, resulting in a positive covariance. Results from single trait analysis revealed a significant QTL for protein percentage. Test statistics were high between 0 and $43 \mathrm{cM}$, with the highest test statistic at $13 \mathrm{cM}$. A suggestive QTL for fat percentage was found in the same region, with the highest test statistic at $14 \mathrm{cM}$.

\section{Identified MQR}

In the same way as described for fat and protein percentage on BTA 6, 105 combinations of traits on 29 chromosomes were tested for the presence of MQR. Based on chromosomewise thresholds, 59 covariances between contrasts were outside the $99 \%$ confidence interval under the null hypothesis. As an overview of the results, the number of MQR per combination of trait categories is presented in Table 1 . The number of MQR and QTL in Table 1 depends on trait characteristics and the number of traits in a trait category. Therefore, to put results in perspective, the number of traits in each trait category and the number of QTL from single trait analysis are presented in Table 1 as well. The 
Table 1. Number of traits per trait category, number of $\mathrm{QTL}^{1}$ from single trait analysis for each trait category, and number of multiple trait quantitative trait regions $(\mathrm{MQR})^{2}$ for combinations of trait categories. In parentheses, the number of traits in each combination of trait categories is listed. Diagonals show the number of MQR involving 2 traits that belong to the same trait category.

\begin{tabular}{|c|c|c|c|c|c|c|}
\hline \multirow[b]{2}{*}{ Trait category } & \multirow{2}{*}{$\begin{array}{l}\text { Traits in } \\
\text { category } \\
\text { (no.) }\end{array}$} & \multirow{2}{*}{$\begin{array}{l}\text { Single } \\
\text { trait QTL } \\
\text { (no.) }\end{array}$} & \multicolumn{4}{|c|}{ MQR for combinations of trait categories ${ }^{3}$ (no.) } \\
\hline & & & Production & $\begin{array}{l}\text { Udder } \\
\text { conformation }\end{array}$ & $\begin{array}{l}\text { Udder } \\
\text { health }\end{array}$ & Fertility \\
\hline Production & 5 & 23 & $9(10)$ & $19(30)$ & $4(10)$ & $5(10)$ \\
\hline Udder conformation & 6 & 17 & & $8(15)$ & $8(12)$ & $5(12)$ \\
\hline Udder health & 2 & 8 & & & 0 (1) & 0 \\
\hline Fertility & 2 & 4 & & & & 1 (1) \\
\hline
\end{tabular}

identified MQR and associated results of relevant single trait analyses are presented in Table 2 ; they are characterized by location and correlation attributable to the $\mathrm{MQR}$ and by the type I error $(\alpha)$ that was used to construct the confidence interval for the covariance.

For combinations between production and udder conformation traits, $19 \mathrm{MQR}$ were found (Table 1). Most of these MQR were located on BTA $13(\mathrm{n}=4$; Table 2) and BTA $14(\mathrm{n}=5)$. Nine MQR involving 2 production traits were found, mainly on BTA 14 (6 MQR) and BTA 6 (2 MQR). For combinations among udder conformation traits, $8 \mathrm{MQR}$ were found. Bos taurus autosome 19 (3 MQR) and BTA 23 (2 MQR) mainly contributed to this number. Bos taurus autosome 14, BTA 19, and BTA 26 each contained $2 \mathrm{MQR}$ affecting an udder conformation trait and an udder health trait.

Chromosomes with $\geq 4 \mathrm{MQR}$ are presented graphically in Figure 2 and are listed in Table 2. Results for these chromosomes will be discussed in more detail. Results for other chromosomes are only presented in Table 2.

BTA 6. On BTA 6, $4 \mathrm{MQR}$ were detected. These were located at 0 (fat and protein percentage), 34 (fore udder attachment and front teat placement), 101 (rear udder height and nonreturn at $56 \mathrm{~d}$ of daughters), and 113 $\mathrm{cM}$ (protein percentage and kilograms of protein). In the single trait analysis, significant QTL for fat and protein percentage were found around $13 \mathrm{cM}$. The correlation between the contrasts of fore udder attachment and front teat placement $(-0.45)$ and the overall genetic correlation between these traits $(0.44)$ differ considerably and have opposite sign. The same applies to the MQR affecting rear udder height and nonreturn of daughters at $56 \mathrm{~d}\left(\mathrm{r}_{\mathrm{MQR}}=0.76 ; \mathrm{r}_{\mathrm{g}}=-0.18\right)$. The correlation attributable to the MQR affecting protein percentage and kilograms of protein was far more negative $(-0.76)$ than the overall genetic correlation, which was close to zero.
BTA 13. On BTA 13, 4 MQR involving production (kg milk and protein and fat percentage) and udder conformation traits (fore udder attachment and udder depth) were located at $0 \mathrm{cM}$. In the single trait analysis, significant QTL for fore udder attachment and udder depth were found in this region. Overall genetic correlations were close to zero for all 4 trait combinations. The MQR correlations were positive for combinations of udder conformation traits and percentage traits $(0.57$ to 0.75 ). The correlation attributable to the MQR affecting fore udder attachment and kilograms of milk was negative $(-0.63)$.

BTA 14. Bos taurus autosome 14 contained $15 \mathrm{MQR}$. Covariances exceeded the confidence interval in the chromosomal region between 0 and $17 \mathrm{cM}$, with most extreme covariances between 7 and $13 \mathrm{cM}$ (Table 2; Figure 2). In Figure 2, only this region of BTA 14 is shown. Thirteen of the $15 \mathrm{MQR}$ involved 1 or 2 production traits, and 6 of these involved 2 production traits. Traits other than production that were affected by these $M Q R$ were fore udder attachment, front teat placement, udder depth, and milking speed. Most overall genetic correlations between the traits involved were close to zero, except for the correlation between kilograms of milk and kilograms of fat (0.37), among percentage traits (0.78) and between milk yield and percentage traits $(-0.59$ and -0.65$)$. Correlations attributable to the MQR were positive between udder conformation and percentage traits (0.46 to 0.55 ) and negative between udder conformation traits and kilograms of milk ( -0.61 to -0.63 ). The MQR correlations among yield traits were comparable with overall genetic correlations, with the exception of the MQR correlation between kilograms of milk and kilograms of fat $(-0.24)$ and kilograms of protein with protein and fat percentages $(-0.62$ to -0.77$)$. The MQR correlations with milking speed were positive for udder conformation traits and fat percentage (0.44 to 0.56 ) and negative for milk 
Table 2. Chromosomes and trait combinations where multiple trait quantitative trait region (MQR) was found with location ${ }^{1}$ of extreme covariance between contrasts. Correlation attributable to the MQR ( $\left.\mathrm{r}_{\mathrm{MQR}}\right)$ and the overall genetic correlation $\left(\mathrm{r}_{\mathrm{g}}\right)$ are indicated. The QTL from single trait analysis are indicated by their location. BTA $=$ Bos taurus autosome.

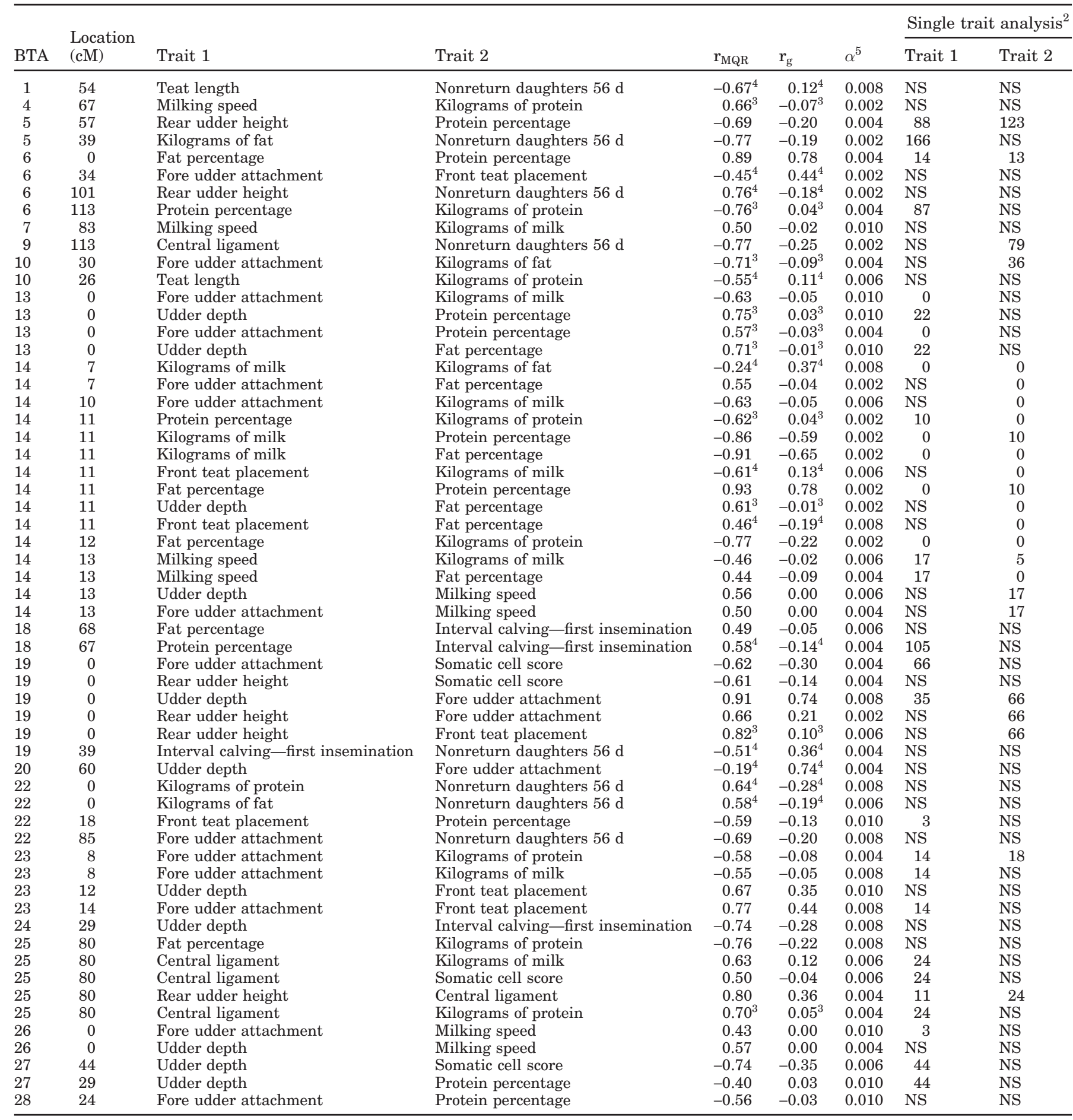

${ }^{1}$ Only locations with most extreme covariance (MQR analysis) or highest test statistic (for single trait analysis) are shown. Appendix 1 contains markers at or flanking these QTL locations.

${ }^{2} \mathrm{NS}=$ No significant or suggestive QTL detected.

${ }^{3}$ Difference between $r_{\mathrm{MQR}}$ and $\mathrm{r}_{\mathrm{g}}$ is $>0.60$.

${ }^{4}$ Difference between $r_{M Q R}$ and $r_{g}$ is $>0.60,\left|r_{g}\right|>0.10$, and $r_{g}$ and $r_{M Q R}$ have opposite sign.

${ }^{5}$ For each test, smallest type I error $(\alpha)$ that yielded a significant result. (Type I errors were estimated empirically, and type I errors $<0.002$ could not be estimated). 

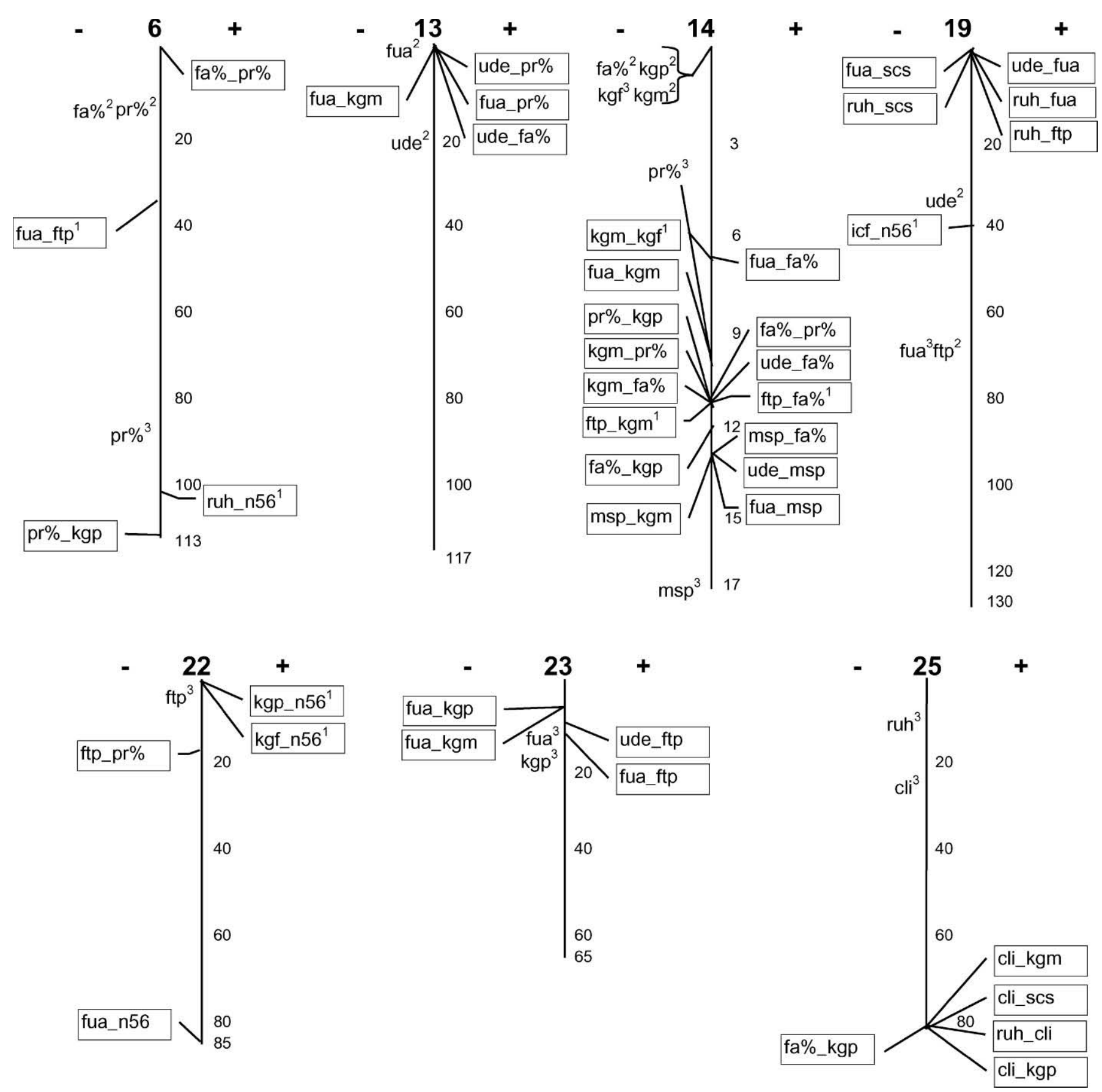

Figure 2. Bos taurus autosomes (BTA) 6, 13, 14, 19, 22, 23, and 25, with regions affecting multiple traits (MQR) as well as significant and suggestive QTL from single trait analysis for traits affected by MQR. Traits are indicated by abbreviations: kgm = kilograms of milk, $\mathrm{fa} \%=$ fat percentage, $\mathrm{pr} \%=$ protein percentage, $\mathrm{kgf}=$ kilograms of fat, kgp = kilograms of protein, fua = fore udder attachment, ftp = front teat placement, tle $=$ teat length, ude $=$ udder depth, ruh $=$ rear udder height, cli $=$ central ligament, $\mathrm{scs}=$ somatic cell score, $\mathrm{msp}=$ milking speed, icf = interval calving - first insemination, and n56 = nonreturn of daughters at $56 \mathrm{~d}$ after insemination. The vertical bar represents the chromosome, with locations indicated in $\mathrm{cM}$. Trait combinations with identified MQR are presented in boxes. The MQR contributing positively to the overall genetic covariance are positioned to the right of the chromosome bar, whereas MQR contributing negatively to the overall genetic covariance are positioned to the left of the chromosome bar. The location of QTL from the single trait analysis is given by the abbreviation of the trait to the left of the chromosome bar. Note the different scale for BTA 14; only the beginning of this chromosome is shown. ${ }^{1} \mathrm{MQR}$ where the sign of the covariance attributable to the MQR was opposite to the sign of the overall genetic covariance. ${ }^{2}$ Significant QTL. ${ }^{3}$ Suggestive QTL. 
yield (-0.46). In the single trait analysis, significant QTL were found for fat percentage, kilograms of milk, and kilograms of protein, whereas suggestive QTL were identified for protein percentage, kilograms of fat, and milking speed in the same region as the $\mathrm{MQR}$.

BTA 19. Five of the $6 \mathrm{MQR}$ on this chromosome are located at $0 \mathrm{cM}$ and affect one of the udder conformation traits and somatic cell score or 2 udder conformation traits. The sixth MQR was at $39 \mathrm{cM}$. The correlation attributable to this MQR affecting the 2 fertility traits, interval calving-first insemination and nonreturn of daughters at $56 \mathrm{~d}$ after insemination, was moderately negative $(-0.51)$, whereas the overall genetic correlation was moderately positive (0.36). The MQR correlation between rear udder height and front teat placement was strongly positive $(0.82)$, whereas the overall genetic correlation between these traits was close to zero. For udder depth, fore udder attachment, and front teat placement, the most probable location for QTL, from the single trait analysis, was at 35, 66, and 66 $\mathrm{cM}$, respectively.

BTA 22. On BTA 22, MQR were found at locations 0 (nonreturn of daughters at $56 \mathrm{~d}$ after insemination with both kilograms of fat and kilograms of protein), 18 (front teat placement and protein percentage), and $85 \mathrm{cM}$ (fore udder attachment and nonreturn at $56 \mathrm{~d}$ after insemination). The single trait analysis only revealed a suggestive QTL at $0 \mathrm{cM}$ for front teat placement. For the $2 \mathrm{MQR}$ at $0 \mathrm{cM}$, there was a large difference between the correlation attributable to the MQR $(0.58$ to 0.64$)$ and the overall genetic correlation $(-0.19$ to -0.28$)$.

BTA 23. The MQR on BTA 23 affected production and udder conformation traits. These MQR were found in the region between 8 and $14 \mathrm{cM}$. In the single trait analysis, suggestive QTL for fore udder attachment and kilograms of protein were found in the same region.

BTA 25. On BTA 25, $5 \mathrm{MQR}$ were located at $80 \mathrm{cM}$. Four of these MQR involved central ligament. Positive effects on central ligament, caused by the MQR, were associated with positive effects for yield traits, somatic cell score, and rear udder height. The overall genetic correlations for the relevant combinations ranged from around zero to moderately positive. There was no significant or suggestive QTL for central ligament at this location nor for the other trait involved in these $4 \mathrm{MQR}$. The highest test statistic for central ligament was found at $24 \mathrm{cM}$. Also for the 5th MQR on this chromosome, involving fat percentage and kilograms of protein, there was no significant or suggestive QTL in the single trait analysis.

\section{MQR with Correlations Deviating from the Overall Genetic Correlation}

For a number of MQR, the correlation caused by the MQR differed largely from the overall genetic correla- tion. In Table 2, correlations are indicated where the difference between MQR correlation and the overall genetic correlation was $\geq 0.60$. Also indicated are MQR where, in addition, the MQR correlation and the overall genetic correlation had opposite sign, and the overall genetic correlation had an absolute value of $\geq 0.10$. This was the case for $12 \mathrm{MQR}$ (Table 2).

Most of the MQR with a correlation deviating from the overall genetic correlation have been indicated in the previous sections already. In addition, positive MQR correlations were observed between milking speed and kilograms of protein (BTA 4), and protein percentage and interval calving - first insemination (BTA 18). Negative MQR correlations were observed between teat length and nonreturn of daughters $56 \mathrm{~d}$ after insemination (BTA 1), fore udder attachment and kilograms of fat (BTA 10), teat length and kilograms of protein (BTA 10), and udder depth and fore udder attachment (BTA 20). The correlation caused by the MQR on BTA 20 affecting udder depth and fore udder attachment was -0.19. On BTA 19, another MQR affecting udder depth and fore udder attachment was observed. The correlation attributable to this MQR was +0.91 , which differs largely from the correlation attributable to the MQR on BTA 20.

\section{DISCUSSION}

\section{Method}

Pleiotropic QTL and closely linked QTL. The method that was used in this paper can identify MQR. The method, however, cannot distinguish between pleiotropic and closely linked QTL. Therefore, the regions where the covariance between contrasts is outside the confidence interval for the expected covariance under the null hypothesis might contain pleiotropic QTL or it might involve regions where two different QTL are located, each affecting a different trait. For example, consider the results found on BTA 14, where the single trait analysis for kilograms of milk gave a peak test statistic at $0 \mathrm{cM}$ and the single trait analysis for milking speed gave a peak test statistic at $17 \mathrm{cM}$ (Figure 2). The covariance between contrasts for kilograms of milk and milking speed deviated most from the expected covariance at $13 \mathrm{cM}$, i.e., in between the most likely locations from the single trait analyses. Given that the confidence interval for the location of a QTL in this type of analysis extends over a wide region, it cannot be excluded that actually this QTL is not a pleiotropic QTL, but 2 linked QTL in a 20-cM region. Methods to distinguish between pleiotropic and closely linked QTL have been developed, for example by Lebreton et al. (1998). They concluded, however, that in common QTL mapping designs, it is unlikely to be able to distinguish 
between pleiotropic QTL and linked QTL at locations 10 to $30 \mathrm{cM}$ apart. Recently, Lund et al. (2003) presented a method, based on combined linkage and linkage disequilibrium analysis, that can distinguish 2 closely linked QTL that are $5 \mathrm{cM}$ apart from a pleiotropic QTL. This method, however, requires a dense linkage map, which is not available in the genome scans applied in dairy cattle so far. With even denser marker maps (e.g., marker intervals of $0.25 \mathrm{cM})$, they expect that more closely linked QTL (e.g., $1 \mathrm{cM}$ apart) can be distinguished from pleiotropic QTL. When the goal is to use the QTL for MAS, the issue of pleiotropy or close linkage is less important than in the case where efforts are undertaken to find the gene or genes. Because of recombination, correlated effects resulting from linkage will disappear over time. In the short term, however, the implications for MAS will not be very different, whether there is pleiotropy or close linkage. It might take many generations before correlated effects caused by linkage will disappear, although that does depend on the distance between the QTL, the magnitude of the QTL effects, and the selection pressure on the QTL.

Permutation test. In the method used in this paper, a permutation test is used to identify MQR. Covariances between contrasts are determined in the original data set as well as in a number of permuted data sets. The applied method consists of computation of the covariance between contrasts and comparison of this covariance with the covariance in permuted data sets. Permutation takes into account the characteristics of the data set, e.g., pedigree structure, marker density, and trait distribution. It is, however, not possible to obtain permuted data sets with a QTL affecting only one trait, which would probably be the ideal situation. As indicated by Schrooten and Bovenhuis (2002), the standard deviation of the covariance may be higher in a data set containing a QTL affecting only one trait, as compared with the permuted data sets having no QTL. Depending on the characteristics of the QTL, this phenomenon can lead to higher type I errors than expected. Elevated covariances between contrasts normally indicate the presence of MQR, but in some cases may also be caused by one QTL affecting one trait. Figure 3 shows the relationship between QTL effect and type I error for a trait with heritability of 0.60 and for QTL effects up to $0.5 \sigma_{\mathrm{a}}$. These results were obtained by simulating a granddaughter design of 20 grandsires with 50 sons per grandsire. Each son had 100 daughters with records on 2 traits. Heritability of the traits was 0.6 and 0.35 , respectively, and the effect of the QTL on trait 1 ranged from 0.1 to $0.5 \sigma_{\mathrm{a}}$. The second trait was not affected by the QTL. One-half of the grandsires were heterozygous for the bi-allelic QTL. Grandsires were informative for markers at 5-cM intervals on a chromosome of $100 \mathrm{cM}$.
The QTL was located at $30 \mathrm{cM}$. One thousand data sets were generated, and each data set was permuted 1000 times and analyzed to obtain 95 and $99 \%$ confidence intervals for the covariance between contrasts. The number of data sets where the covariance between contrasts was outside the confidence interval was counted to obtain the real type I error. Figure 3 shows that type I error increases with increasing effects of the QTL. The impact on type I error rates is small for QTL effects up to $0.2 \sigma_{\mathrm{a}}$.

\section{Literature}

Lipkin et al. (2002) examined pleiotropic effects of QTL on milk yield, protein percentage, and protein yield using selective DNA pooling in regions of the genome previously found to be affecting protein percentage. Because of the algebraic dependence of the analyzed traits, it is likely that a relatively high number of QTL would be declared to be pleiotropic. Combining results, Lipkin et al. (2002) concluded that there might be about 40 suggestive QTL on the genome affecting all 3 traits. Chromosomes and markers involved were not specified, and, therefore, it is not possible to compare the results found by Lipkin et al. (2002) on pleiotropic QTL with results from the current study.

For a large number of MQR presented in Table 2, QTL for one of the traits involved have been reported in literature. Most studies only reported on a limited number of traits; therefore, only a limited number of MQR found in the current research could be confirmed from literature, especially those on BTA 6 and BTA 14, which affected production traits. These will be mentioned here, and the QTL from literature affecting one of the traits involved in the MQR from Table 2 will not be discussed.

BTA 6. Numerous researchers have studied QTL on BTA 6, indicating the presence of multiple QTL on this chromosome (reviewed by Mosig et al., 2001). Spelman et al. (1996) found a QTL affecting both protein percentage and milk yield in 2 grandsire families. Using interval mapping and multiple regression analysis in a daughter design, Ron et al. (2001) found results supporting the hypothesis that one QTL is segregating in 2 different families and that this QTL affects 5 production traits: kilograms of milk, fat percentage, protein percentage, kilograms of fat, and kilograms of protein. This QTL was located close to $55 \mathrm{cM}$, which corresponds to $40 \mathrm{cM}$ on the map used in our study. Freyer et al. (2002) reported a QTL on BTA 6 that affected both protein yield and fat yield. This QTL was located at $70 \mathrm{cM}$, which corresponds to $52 \mathrm{cM}$ on the map used in the current study. Freyer et al. (2002) also found QTL at the casein cluster that affected several production 


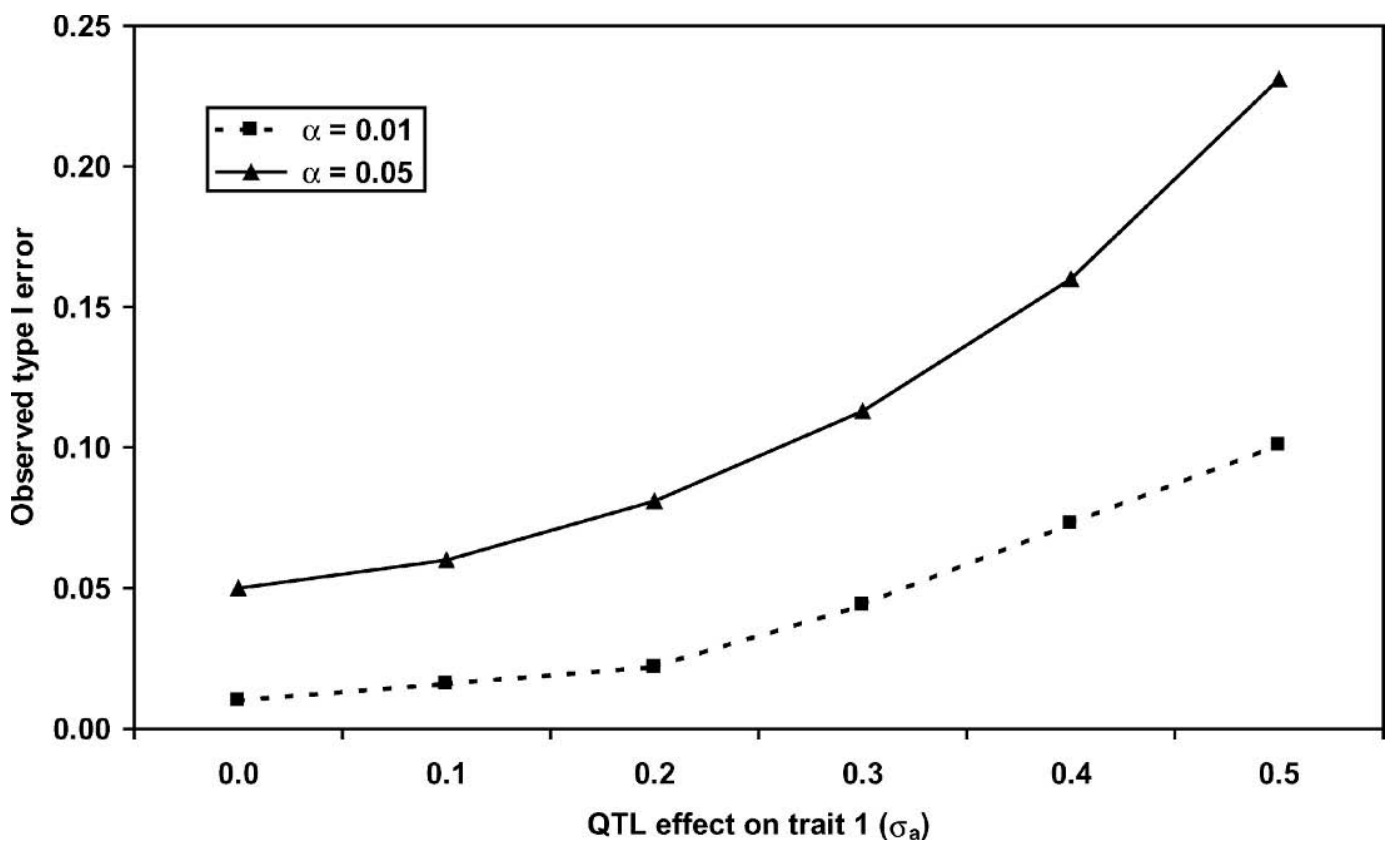

Figure 3. Probability (= observed type I error) to detect a region affecting multiple traits in a typical granddaughter design (20 grandsires, 50 sons per grandsire, 100 daughters per son). A QTL effect was simulated only for trait 1 ; the effect ranged from 0 to $0.5 \sigma_{\mathrm{a}}$. Type I error is set to 0.01 or 0.05 .

traits. The casein cluster corresponds to a location of $95 \mathrm{cM}$ on the map used in the current study. Compared with the MQR involving production traits in our study, QTL presented by Freyer et al. (2002) were located more toward the center of the chromosome.

BTA 14. Recently, a mutation in the DGAT1 gene on BTA 14 was reported, and an effect on production traits was noted (Grisart et al., 2002). This gene has an effect on several milk production traits and is located in the region between the first 2 markers used in this study, close to $0 \mathrm{cM}$. The substitution effects for milk production traits were kilograms of milk, -158 ; fat percentage, $+0.17 \%$; protein percentage, $+0.04 \%$; kilograms of fat, +5.23 ; and kilograms of protein, -2.82 (Grisart et al., 2002). Effects were expressed in terms of daughter yield deviations. Based on these effects, an increase of kilograms of milk, for example, is expected to result in a decrease of fat percentage and a decrease of kilograms of fat. In the current study, which consists of partly the same data as used by Grisart et al. (2002), a region on BTA 14 affecting multiple milk production traits was reported (Figure 2). For all combinations of production traits presented in Figure 2, the effects on the traits involved were in agreement with the effects of the gene as presented by Grisart et al. (2002), which supports the results presented in this study. The MQR for production traits on BTA 14 in the current study showed most extreme covariances at 7,11 , and $12 \mathrm{cM}$, which agrees with the location of the DGAT1 gene close to $0 \mathrm{cM}$.

\section{MQR with Correlations Deviating from the Overall Genetic Correlation}

In Table 2, a number of MQR are shown for which the covariance caused by the MQR and the overall genetic covariance differ largely. The overall genetic covariance is the result of the summation of all covariances attributable to individual QTL, either pleiotropic or closely linked. The contribution of each MQR to the overall genetic covariance depends on the size and the sign of the effects on the traits involved. If the genetic correlation is strongly positive, it is expected that the covariance at most of the individual MQR is positive. There might, however, be a few MQR with a negative contribution to the overall genetic covariance, i.e., $\mathrm{MQR}$ with correlations that strongly deviate from the overall genetic correlation. As was shown by Schrooten and Bovenhuis (2002), the statistical power to detect these $\mathrm{MQR}$ is increased compared with MQR that do not deviate from overall genetic correlations. For pairs of traits with high genetic correlations, it is expected that there are relatively few MQR that strongly deviate from the overall genetic correlation, but the power to find these MQR is higher (Korol et al., 1995; Schrooten and Bovenhuis, 2002). For cases in which the overall genetic correlation between traits is unfavorable, MAS for MQR that strongly deviate from the overall genetic correlation offers excellent opportunities to achieve progress for 
both traits. This was demonstrated by de Koning and Weller (1994).

\section{Comparison with Results from Single Trait Analysis}

The analysis described in this paper resulted in regions affecting multiple traits, in some cases affecting traits for which no QTL were detected in the single trait analysis. As was discussed by Korol et al. (1995), methods that use information from multiple traits have higher power, which can account for a number of QTL not previously identified. However, in the present study, we did not account for multiple testing when identifying MQR. In total, 3045 tests were performed, and MQR were reported when the covariance was outside the $99 \%$ chromosomewise confidence interval. The type I error of 0.01 was divided over both sides of the interval when constructing the confidence interval. In the single trait analysis, 435 tests were performed, and QTL were considered suggestive when the chromosomewise type I error was $<0.0345$. Combining the number of detected QTL and MQR (Table 1) with the respective number of tests yields a false discovery rate (Benjamini and Hochberg, 1995) of $(0.0345 \times 435) / 52=0.29$ for the single QTL analysis and $(0.01 \times 3045) / 59=0.52$ for the MQR analysis. The latter is relatively high. Therefore, MQR reported here should be considered suggestive rather than significant. However, it was considered important to present these results to assess potential consequences of using the given MQR in MAS.

To compare results from single trait analysis and the analysis described in this paper, consider for example the results for BTA 25. Four MQR involving central ligament were detected at $80 \mathrm{cM}$, whereas, in the single trait analysis for this trait, a suggestive QTL was located at $24 \mathrm{cM}$. At first glance, these results do not seem to be in agreement. A within-family analysis on this chromosome for central ligament, however, indicated 2 families with suggestive QTL at $80 \mathrm{cM}$, in addition to other families with suggestive QTL for central ligament at or around $24 \mathrm{cM}$ (results not shown). Within-family contrasts for other traits, such as rear udder height, were significant in these families. As a result, the covariance between contrasts for these traits was outside the confidence interval for the expected covariance under the null hypothesis. Although these QTL were not detected in the across-family analysis, they can be detected in a within-family analysis and also by the method used in this paper.

The MQR identified in the current study include a number of potentially interesting regions from the point of view of selection. For example, the MQR on BTA 25 should be explored further: favorable effects on kilograms of milk and kilograms of protein are associated with favorable effects on udder traits, especially central ligament. Udder traits such as rear udder height, front teat placement, fore udder attachment, and udder depth are affected by MQR on BTA 19, which could be exploited in MAS. Favorable effects of MQR on BTA 13, on udder traits such as udder depth and fore udder attachment, are associated with favorable effects on fat and protein percentages.

\section{CONCLUSIONS}

A number of chromosomal regions affecting multiple traits in dairy cattle have been identified. These regions might contain a QTL with a pleiotropic effect on both traits or they might contain 2 different QTL, each affecting one of the traits. Chromosomal regions influencing multiple traits were found on almost all chromosomes, but especially on BTA $6,13,14,19,22,23$, and 25. Eight MQR involving udder conformation and udder health and $4 \mathrm{MQR}$ involving production traits and udder health were found. Five MQR were identified for combinations of fertility and udder conformation traits, and another $5 \mathrm{MQR}$ were identified for combinations of fertility and production traits.

\section{ACKNOWLEDGMENTS}

We thank Johan van Arendonk and Sijne van der Beek for their comments on the manuscript and Michel Georges' group, Department of Genetics, University of Liège (Belgium), for providing the genotypes. We appreciate the financial support by Holland Genetics.

\section{REFERENCES}

Ashwell, M. S., Y. Da, C. P. Van Tassell, P. M. Vanraden, R. H. Miller, and C. E. Rexroad, Jr. 1998. Detection of putative loci affecting milk production and composition, health, and type traits in a United States Holstein population. J. Dairy Sci. 81:3309-3314.

Benjamini, Y., and Y. Hochberg. 1995. Controlling the false discovery rate: A practical and powerful approach to multiple testing. J. R. Statist. Soc. 57:289-300.

Blott, S., J. J. Kim, S. Moisio, A. Schmidt-Kuntzel, A. Cornet, P. Berzi, N. Cambisano, C. Ford, B. Grisart, D. Johnson, L. Karim, P. Simon, R. Snell, R. Spelman, J. Wong, J. Vilkki, M. Georges, F. Farnir, and W. Coppieters. 2003. Molecular dissection of a quantitative trait locus. A phenylalanine-to-tyrosine substitution in the transmembrane domain of the bovine growth hormone receptor is associated with a major effect on milk yield and composition. Genetics 163:253-266.

Churchill, G. A., and R. W. Doerge. 1994. Empirical threshold values for quantitative trait mapping. Genetics 138:963-971.

de Koning, G. J., and J. I. Weller. 1994. Efficiency of direct selection on quantitative trait loci for a two-trait breeding objective. Theor. Appl. Genet. 88:669-677.

Falconer, D. S., and T. F. C. Mackay. 1996. Introduction to Quantitative Genetics. Longman, Essex, United Kingdom.

Freyer, G., C. Kühn, R. Weikard, Q. Zhang, M. Mayer, and I. Hoeschele. 2002. Multiple QTL on chromosome six in dairy cattle affecting yield and content traits. J. Anim. Breed. Genet. 119:69-82. 
Georges, M., D. Nielsen, M. Mackinnon, A. Mishra, R. Okimoto, A. T. Pasquino, L. S. Sargeant, A. Sorensen, M. R. Steele, X. Zhao, J. E. Womack, and I. Hoeschele. 1995. Mapping quantitative trait loci controlling milk production in dairy cattle by exploiting progeny testing. Genetics 139:907-920.

Grisart, B., W. Coppieters, F. Farnir, L. Karim, C. Ford, P. Berzi, N. Cambisano, M. Mni, S. Reid, P. Simon, R. Spelman, M. Georges, and R. Snell. 2002. Positional candidate cloning of a QTL in dairy cattle: Identification of a missense mutation in bovine DGAT1 gene with major effect on milk yield and composition. Genome Res. 12:222-231.

Jiang, C., and Z.-B. Zeng. 1995. Multiple trait analysis of genetic mapping for quantitative trait loci. Genetics 140:1111-1127.

Kashi, Y., E. Hallerman, and M. Soller. 1990. Marker assisted selection of candidate young bulls for progeny testing programmes. Anim. Prod. 51:63-74.

Knott, S. A., J. M. Elsen, and C. S. Haley. 1994. Multiple marker mapping of quantitative trait loci in half sib populations. Proc. 5th World Congr. Genet. Appl. Livest. Prod., Guelph, Canada XXI:33-36.

Knott, S. A., and C. S. Haley. 2000. Multitrait least squares for quantitative trait loci detection. Genetics 156:899-911.

Korol, A. B., Y. I. Ronin, and V. M. Kirzhner. 1995. Interval mapping of quantitative trait loci employing correlated trait complexes. Genetics 140:1137-1147.

Korol, A. B., Y. I. Ronin, E. Nevo, and P. Hayes. 2001. Enhanced efficiency of quantitative trait loci mapping analysis based on multivariate complexes of quantitative traits. Genetics 157:1789-1803.

Lebreton, C. M., P. M. Visscher, C. S. Haley, A. Semikhodskii, and S. A. Quarrie. 1998. A nonparametric bootstrap method for testing close linkage vs. pleiotropy of coincident quantitative trait loci. Genetics 150:931-943.

Lipkin, E., G. Grosman, E. Tchourzyna, A. Friedmann, and M. Soller. 2002. QTL affecting milk protein percent also affect milk yield and protein yield. Proc. 7th World Congr. Genet. Appl. Livest. Prod., Montpellier, France 31:55-58.
Lund, M. S., P. Sørensen, B. Guldbrandtsen, and D. A. Sorensen. 2003. Multitrait fine mapping of quantitative trait loci using combined linkage disequilibria and linkage analysis. Genetics 163:405-410.

Meuwissen, T. H., and J. A. M. Van Arendonk. 1992. Potential improvements in rate of genetic gain from marker-assisted selection in dairy cattle breeding schemes. J. Dairy Sci. 75:1651-1659.

Mosig, M. O., E. Lipkin, G. Khutoreskaya, E. Tchourzyna, M. Soller, and A. Friedmann. 2001. A whole genome scan for quantitative trait loci affecting milk protein percentage in Israeli-Holstein cattle, by means of selective milk DNA pooling in a daughter design, using an adjusted false discovery rate criterion. Genetics 157:1683-1698.

Ron, M., D. Kliger, E. Feldmesser, E. Seroussi, E. Ezra, and J. I. Weller. 2001. Multiple quantitative trait locus analysis of bovine chromosome 6 in the Israeli Holstein Population by a Daughter Design. Genetics 159:727-735.

Schrooten, C., H. Bovenhuis, W. Coppieters, and J. A. M. Van Arendonk. 2000. Whole genome scan to detect quantitative trait loci for conformation and functional traits in dairy cattle. J. Dairy Sci. 83:795-806.

Schrooten, C., and H. Bovenhuis. 2002. Detection of pleiotropic effects of quantitative trait loci in outbred populations using regression analysis. J. Dairy Sci. 85:3503-3513.

Spelman, R. J., W. Coppieters, L. Karim, J. A. M. van Arendonk, and H. Bovenhuis. 1996. Quantitative trait loci analysis for five milk production traits on chromosome six in the Dutch HolsteinFriesian population. Genetics 144:1799-1808.

Weller, J. I., Y. Kashi, and M. Soller. 1990. Power of daughter and granddaughter designs for determining linkage between marker loci and quantitative trait loci in dairy cattle. J. Dairy Sci. 73:2525-2537.

Weller, J. I., G. R. Wiggans, P. M. vanRaden, and M. Ron. 1996. Application of a canonical transformation to detection of quantitative trait loci with the aid of genetic markers in a multi-trait experiment. Theor. Appl. Genet. 92:998-1002.

\section{APPENDIX}

Table A1. Markers at or flanking the QTL locations listed in Table 2.

\begin{tabular}{rlllll}
\hline BTA & $\begin{array}{l}\text { Location } \\
(\mathrm{cM})\end{array}$ & Marker or flanking markers & BTA & $\begin{array}{l}\text { Location } \\
(\mathrm{cM})\end{array}$ & Marker or flanking markers \\
\hline 1 & 54 & BMS711, TGLA57 & 14 & 12 & BULGE034, BULGE017 \\
4 & 67 & BM6458, TGLA116 & 14 & 13 & BULGE017 \\
5 & 39 & BP1, AGLA293 & 14 & 17 & CSSM66 \\
5 & 57 & AGLA293, AGLA254 & 18 & 67,68 & BM7109, ILSTS002 \\
5 & 88 & AGLA254, IGF1 & 18 & 105 & IDVGA55, TGLA227 \\
5 & 123 & IGF1, BM315 & 19 & 0 & BM9202 \\
5 & 166 & ETH152 & 19 & 35,39 & TGLA94, URB044 \\
6 & 0 & ILSTS090 & 19 & 66 & BMS2503 \\
6 & 13,14 & MCM53, URB016 & 20 & 60 & BMS703, BM5004 \\
6 & 34 & BMS2508, BM143 & 22 & 0 & CSSM26 \\
6 & 101 & BP7, BM2320 & 22 & 3,18 & CSSM26, CSSM6 \\
6 & 113 & BM2320 & 22 & 85 & HMH1R \\
7 & 83 & TGLA164, AGLA260 & 23 & 8 & BM47, RM033 \\
9 & 79 & TGLA73 & 23 & $12,14,18$ & RM033, BM1258 \\
9 & 113 & CSSM56 & 24 & 29 & AGLA269, BMS66 \\
10 & 26,30 & BM1237, BRRIBOold & 25 & 11 & RM074 \\
10 & 36 & BRRIBOold & 25 & 24 & TGLA40 \\
13 & 0 & TGLA23 & 25 & 80 & AF5 \\
13 & 22 & BMC1222 & 26 & 0 & TGLA22 \\
14 & 0 & BULGE011 & 26 & 3 & TGLA22, HEL11 \\
14 & 5 & BULGE030 & 27 & 29 & CSSM43 \\
14 & 7 & BULGE030, BULGE036 & 27 & 44 & HUJI3 \\
14 & 10 & BULGE036, BULGE034 & 28 & 24 & BMS362 \\
14 & 11 & BULGE034 & & & \\
\hline
\end{tabular}

